\title{
Eco-Friendly Pretreatment of Titanium Turning Scraps and Subsequent Preparation of Ferro-Titanium Ingots
}

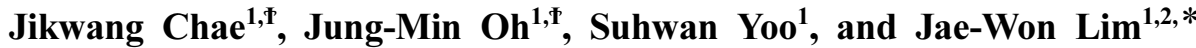 \\ ${ }^{1}$ Division of Advanced Materials Engineering, College of Engineering, Chonbuk National University, Jeonju 54896, \\ Republic of Korea \\ ${ }^{2}$ The Research Institute of Mineral Resources and Energy Development, Chonbuk National University, Jeonju 54896, \\ Republic of Korea
}

\begin{abstract}
In this study, an eco-friendly pretreatment process was developed to recycle titanium turning scraps and ferro-titanium ingots with low gaseous impurities were prepared using recycled titanium turning scraps. The amount of gaseous impurities of titanium scraps before removing the machining oils on the surface was as high as $20000 \mathrm{ppm}$. To remove these oils, the eco-friendly pretreatment solution excluding acid solution or organic solvent was developed. As a result, the respective gaseous impurities of oxygen, nitrogen and carbon showed reduction ratio of $54.0 \%, 96.2 \%$, and $98.4 \%$ as compared to the raw material under the optimum condition of $\mathrm{NaOH}+\mathrm{Na}_{4} \mathrm{P}_{2} \mathrm{O}_{7}$. When a Fe-Ti ingot was prepared with the eco-friendly pretreatment scraps under the optimum conditions, the total content of gaseous impurities in the Fe-Ti ingot with pretreated Ti scraps was reduced by $81 \%(\mathrm{O}, \mathrm{N}, \mathrm{C}=1365 \mathrm{ppm})$ compared to the $\mathrm{Fe}-\mathrm{Ti}$ ingot with raw Ti scraps.
\end{abstract}

(Received March 18, 2019; Accepted July 23, 2019)

Keywords: titanium, ferro-titanium, scrap, recycling, gaseous impurity

\section{INTRODUCTION}

Titanium is a typical light-weight metal similar to aluminum and is known as a new material with high specific strength and corrosion resistance, as well as especially high biocompatibility [1-3]. Despite these excellent properties, however, the cost of the material is very high compared to other structural materials. Norgate et al. [4] showed that the energy used to produce titanium is up to 16 times higher than that needed to produce the same weight of steel, and more than $70 \%$ higher than the amount required for aluminum. Because of the extreme oxygen affinity of titanium, it takes a substantial amount of energy and processing to reduce it from titanium oxide to metallic titanium. Therefore, industry and many researchers are making efforts to develop recycling technology for titanium scraps [5-7].

In order to recycle titanium scraps, a powder is produced

\footnotetext{
${ }^{\mathrm{T} T}$ These authors contributed equally to this work as the first author. - 채지광·유수환: 석사과정, 오정민: 조교, 임재원: 교수

*Corresponding Author: Jae-Won Lim

[Tel: +82-63-270-2307, E-mail: jwlim@jbnu.ac.kr]

Copyright (c) The Korean Institute of Metals and Materials
}

by the HDH (hydrogenation-dehydrogenation) method using sound scraps and a deoxidation process is applied to produce titanium powder with low oxygen content [8]. It has also been reported that high-purity titanium ingots can be produced by removing metallic impurities in scraps through a high-temperature melting method [9]. Ferro-titanium is also produced through titanium scraps as a major additive used in the steel industry [10]. Ferro-titanium is used for alloying of special steels, in which titanium is a small amount of the alloy, or for inhibiting the sensitization by inhibiting carbon and chromium carbide formation in the microstructure during the production of stainless steel $[11,12]$. Titanium turning scraps have been used for the purpose of minimizing the manufacturing cost of ferro-titanium ingots. However, if an eco-friendly pretreatment, such as removal of cutting oil or processing oil remaining on the surface of the scraps, is not performed, the presences of gaseous impurities such as oxygen, nitrogen, and carbon will adversely affect the properties of the final ferro-titanium ingot.

Machining oils are inevitably present on the surface of titanium turning scraps, and if they are not completely removed, they will also have an adverse effect as impurities 
in scrap applications. In order to completely remove these oils, acids, bases, and organic solvents are generally used. Hydrofluoric acid is used for the pickling of titanium, and the reaction can be explosive due to the large surface area when the turning scrap is immersed in the acid solution. TCE (trichloroethylene) is mainly used for cleaning using organic solvents, and TCE is classified as a carcinogen. The use of acids and organic solvents can lead to operator safety and health concerns and environmental problems. Therefore, it is necessary to remove oil from the surface by using a safe and environmentally friendly base solution with less reactivity than acids and organic solvents.

In earlier paper, there have been studies to recycle titanium scraps recycled by using a rod or pipe [13], but there have been few studies to manufacture ferro-titanium alloy by washing titanium scrap. Also, the pretreatment of zirconium alloy using base solution was carried out [14]. However, the effect of oxygen, nitrogen, and carbon contents on the specimen by base solution was not investigated. In this study, we investigated the effect of residual oil on the gas impurity content of the final ferro-titanium ingot by determining the proper composition of the pretreatment solution of titanium turning chip scraps.

\section{EXPERIMENTAL PROCEDURES}

In order to remove oil remaining in the titanium turning scraps, the samples of titanium scraps were collected and immersed in a 0.5 to $5 \mathrm{M}$ aqueous $\mathrm{NaOH}$ solution for $10 \mathrm{~min}$. The reason for the immersion for 10 minutes is that oxidation will occur when the titanium is immersed in the aqueous solution of $\mathrm{NaOH}$ for a long time [15]. Stirring was not carried out so that it could see the effect of the solution only, and then the samples were washed with water three times and dried in a vacuum oven at $70{ }^{\circ} \mathrm{C}$ for $2 \mathrm{~h}$. Also, tetrasodium pyrophosphate $\left(\mathrm{Na}_{4} \mathrm{P}_{2} \mathrm{O}_{7}\right.$, TSPP) was added to a $2 \mathrm{M}$ aqueous solution of $\mathrm{NaOH}$, and additional samples were immersed in this mixture at room temperature. After completing the same procedure as with the $\mathrm{NaOH}$ aqueous solution, $\mathrm{C}, \mathrm{O}$, and $\mathrm{N}$ analyses of all specimens were performed.

The ferro-titanium ingot was prepared by electrolytic iron and pretreated titanium turning scraps in an arc melting furnace. Before the arc melting, $14 \mathrm{~g}$ of titanium turning scraps and $6 \mathrm{~g}$ of electrolytic iron were mixed, compressed at $50 \mathrm{MPa}$ using a $30 \mathrm{~mm}$ diameter compaction mold, and then melted in a high purity argon atmosphere for $1 \mathrm{~min}$. In order to obtain a homogeneous composition, the sample was turned over and again melted for $1 \mathrm{~min}$ for a total of $2 \mathrm{~min}$. Then, the specimen was cut, and its cross section was polished with $\mathrm{SiC}$ sandpaper; next, X-ray diffraction (XRD) study was performed (SHIMAZU, LabX XRD-6100, $40 \mathrm{kV}, 30 \mathrm{~mA}$, $\mathrm{Cu}-\mathrm{K}$ radiation). The specimens were further polished up to \# 2000 sandpaper followed by $1 \mu \mathrm{m}$ alumina powder. To analyze the microstructure, the polished surface was observed through a scanning electron microscope (SEM) after etching with Keller's reagent. Energy dispersive X-ray spectroscopy (EDS) was used to analyse the microstructure. $\mathrm{C}$, O, and $\mathrm{N}$ analysis (Eltra CS-800, ON-900) were performed to determine the content of non-metallic impurities in the specimen. Also, oxidation at high temperature was carried out using heating rate of $10^{\circ} \mathrm{C} / \mathrm{min}$, under air atmosphere.

\section{RESULTS AND DISCUSSION}

The titanium scraps used as the raw material in this study were turning scraps after milling machining. Their appearance is shown in Fig. 1(a). The surface of the scrap was observed with an optical microscope, and it is also shown in Fig. 1(b). A large amount of oil remained on the surface of the scraps, and it can be seen that it is distributed all over the surface. The gaseous analysis was carried out to investigate the influence of the residual oil on the gaseous impurities of oxygen, nitrogen, and carbon of scrap material. The contents of oxygen, nitrogen, and carbon in the titanium scraps were $2480,445,17140 \mathrm{ppm}$. The gaseous impurity content of the raw titanium scrap was higher than that of the bulk material, and the content of carbon was particularly high at $17140 \mathrm{ppm}$. This is because the main component of the oil is carbon, and it is expected to affect the final product.

The eco-friendly pretreatment solution used for the raw titanium scraps is an aqueous $\mathrm{NaOH}$ solution, which is currently used in the degreasing process of metals. The degreasing process used by the $\mathrm{NaOH}$ solution is known to be the reaction of:

$$
R C O O R^{\prime}+\mathrm{NaOH} \rightarrow \mathrm{RCOONa}+\mathrm{R}^{\prime} \mathrm{OH}[16] .
$$



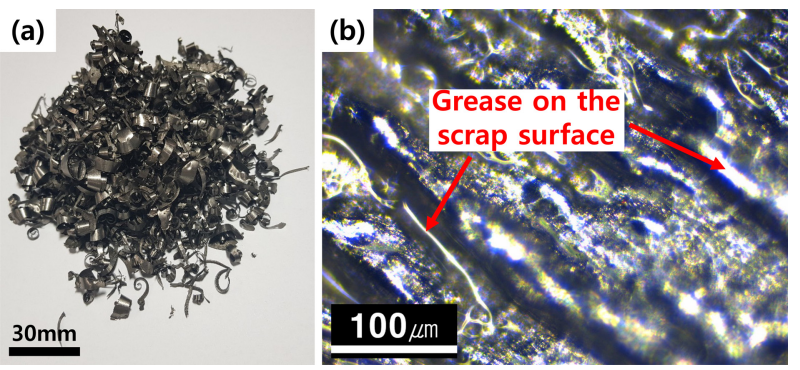

Fig. 1. Appearance of titanium turning scraps (a) and surface appearance of titanium turning scraps by optical microscope (b).

According to Equation (1), the fatty acid salt formed by the reaction of $\mathrm{NaOH}$ and oil acts as a surfactant to remove the oil on the surface of the titanium scrap.

First, the optimum condition was derived based on the oxygen content by varying the molar concentration of $\mathrm{NaOH}$ solution from $0.5 \mathrm{M}$ to $5 \mathrm{M}$. The oxygen content of the titanium scraps after degreasing through the solution of each molar concentration was analyzed and are shown in Fig. 2(a). As the molar concentration of $\mathrm{NaOH}$ increased, the oxygen content took on values of $2065,1930,1665,1730,1710$, and $1820 \mathrm{ppm}$. The oxygen content in the titanium decreased as the molar concentration of $\mathrm{NaOH}$ increased and decreased to the minimum at $2 \mathrm{M}$. It is thought that the increase in oxygen content at the $\mathrm{NaOH}$ concentration of $5 \mathrm{M}$ is due to the high concentration of $\mathrm{NaOH}$ [15]. The mechanism of titanium oxidation in aqueous solution of $\mathrm{NaOH}$ is as follows [15].

$$
\begin{aligned}
& \mathrm{TiO}_{2}+\mathrm{OH}^{-} \rightarrow \mathrm{HTiO}_{3}^{-} \\
& \mathrm{Ti}+3 \mathrm{OH}^{-} \rightarrow \mathrm{Ti}(\mathrm{OH})_{3}^{+}+4 e^{-} \\
& \mathrm{Ti}(\mathrm{OH})_{3}^{+}+e^{-} \rightarrow \mathrm{TiO}_{2} \cdot \mathrm{H}_{2} \mathrm{O}+1 / 2 \mathrm{H}_{2} \uparrow \\
& \mathrm{Ti}(\mathrm{OH})_{3}^{+}+\mathrm{OH}^{-} \leftrightarrow \mathrm{Ti}(\mathrm{OH})_{4} \\
& \mathrm{TiO}_{2} \cdot \mathrm{nH}_{2} \mathrm{O}+\mathrm{OH}^{-} \leftrightarrow \mathrm{HTiO}_{3}^{-} \cdot \mathrm{nH}_{2} \mathrm{O}
\end{aligned}
$$

As shown in Equation (2), the passive layer on the $\mathrm{Ti}$ surface reacts with $\mathrm{OH}^{-}$ions in the aqueous solution to form $\mathrm{HTiO}_{3}{ }^{-}$ions, which dissolves into the aqueous solution to remove the protective coating. The exposed metallic Ti reacts with $\mathrm{OH}^{-}$ions to form titanium hydroxide ions (3). And a titanium hydroxide ion combined with an electron produces titanium dioxide and hydrogen gas or reacts with additional $\mathrm{OH}^{-}$ion produces $\mathrm{Ti}(\mathrm{OH})_{4}$ as shown in equation (5). The
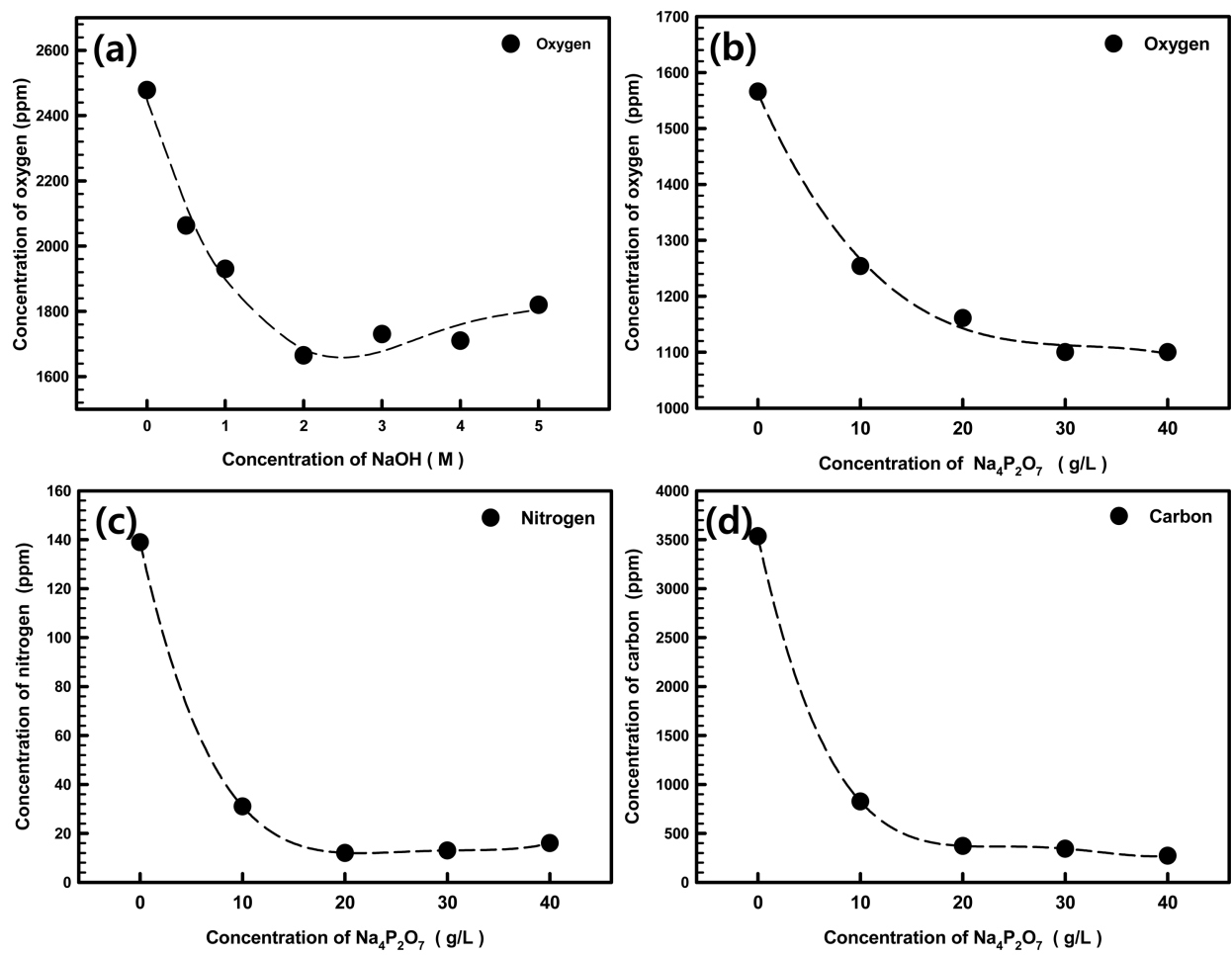

Fig. 2. Concentration of gaseous impurities in the titanium scraps as a function of solution concentration: (a) oxygen concentration in titanium scraps as a function of $\mathrm{NaOH}$ concentration, (b) oxygen, (c) nitrogen, and (d) carbon concentration in titanium scraps as a function of $\mathrm{Na}_{4} \mathrm{P}_{2} \mathrm{O}_{7}$ concentration. 
generated titanium dioxide reacts again to produce $\mathrm{HTiO}_{3}^{-}$ ions. Then the oxidation process of titanium is repeated. Therefore, the molar concentration of the $\mathrm{NaOH}$ solution in the eco-friendly pretreatment solution of this study was set at $2 \mathrm{M}$. Under these conditions, the content of nitrogen was 140 ppm, and the content of carbon was 5886 ppm.

The $\mathrm{NaOH}$ solution solely removed the gaseous impurities in the scraps, but the remaining carbon content was as high as $5886 \mathrm{ppm}$. Then, as the next step, $\mathrm{Na}_{4} \mathrm{P}_{2} \mathrm{O}_{7}$ was added to the two molar solution of $\mathrm{NaOH}$. In general, phosphates are known to have peptizing action and to disperse evenly the oil particles to prevent re-adsorption to the specimen. In particular, $\mathrm{Na}_{4} \mathrm{P}_{2} \mathrm{O}_{7}$ is known to facilitate the removal of mineral oil $[16,17]$. The gaseous impurity contents of the titanium scraps after degreasing through the $2 \mathrm{M} \mathrm{NaOH}+$ $\mathrm{Na}_{4} \mathrm{P}_{2} \mathrm{O}_{7}$ solution are shown in Figs. 2(b) - 2(d). The oxygen content of scraps that had been degreased with $\mathrm{NaOH}$ alone was $1570 \mathrm{ppm}$. As the amount of $\mathrm{Na}_{4} \mathrm{P}_{2} \mathrm{O}_{7}$ solution was increased, the oxygen content changed to 1250, 1160, 1090, and $1140 \mathrm{ppm}$. The nitrogen content was also lowered from the initial $140 \mathrm{ppm}$ to $31,12,13$, and $17 \mathrm{ppm}$, just as with the oxygen. Particularly, the carbon content decreased significantly from the initial $5886 \mathrm{ppm}$ to 830, 370, 345, and $270 \mathrm{ppm}$. The contents of oxygen, nitrogen, and carbon decreased with the increasing amount of $\mathrm{Na}_{4} \mathrm{P}_{2} \mathrm{O}_{7}$ and the results at $30 \mathrm{~g} / \mathrm{L}$ and $40 \mathrm{~g} / \mathrm{L}$ were almost the same. The gaseous impurity contents of the raw titanium turning scraps after treatment with $\mathrm{NaOH} 2 \mathrm{M}+40 \mathrm{~g} / \mathrm{L} \mathrm{Na} \mathrm{P}_{2} \mathrm{O}_{7}$ are shown in Table 1. Finally, removal efficiencies were $54.0 \%$ for oxygen, $96.2 \%$ for nitrogen and $98.4 \%$ for carbon through the eco-friendly pretreatment solution containing $\mathrm{NaOH} 2 \mathrm{M}+40 \mathrm{~g} / \mathrm{L}$ $\mathrm{Na}_{4} \mathrm{P}_{2} \mathrm{O}_{7}$. The removal rate of oxygen is lower than that of nitrogen and carbon, but $1140 \mathrm{ppm}$ is equivalent to grade 1 of commercial titanium.

Next, a Fe-Ti alloy ingot was prepared using the titanium turning scraps pretreated with $\mathrm{NaOH} 2 \mathrm{M}+40 \mathrm{~g} / \mathrm{L} \mathrm{Na} \mathrm{P}_{2} \mathrm{O}_{7}$.

Table 1. Content of gaseous impurities in the titanium turning scraps (ppm).

\begin{tabular}{cccc}
\hline \hline Raw material & Oxygen & Nitrogen & Carbon \\
\hline $\begin{array}{c}\text { Ti turning scraps } \\
\mathrm{NaOH} 2 \mathrm{M}\end{array}$ & 2480 & 445 & 17140 \\
$+\mathrm{Na}_{4} \mathrm{P}_{2} \mathrm{O}_{7} 40 \mathrm{~g} / \mathrm{L}$ & 1140 & 17 & 270 \\
\hline
\end{tabular}

In this study, the influence of residual oil on the gaseous content of the Fe-Ti alloy ingots with and without ecofriendly pretreated scraps was investigated. Throughout the rest of this paper, a Fe-Ti ingot using raw titanium scraps will be labeled as "raw Fe-Ti ingot", and a Fe-Ti ingot using pretreated titanium scraps will be labeled as "pretreated FeTi ingot". Figure 3(a) and 3(b) show the appearance of raw $\mathrm{Fe}-\mathrm{Ti}$ and pretreated Fe-Ti ingots. Non-metallic impurities of the two Fe-Ti alloy ingots were analyzed and are shown in Table 2. The total content of gaseous impurities in the raw Fe-Ti ingot was $7255 \mathrm{ppm}$ and that of the pretreated Fe-Ti was $1365 \mathrm{ppm}$. On the other hand, the amount of oxygen and carbon in the pretreated Fe-Ti did not reach the level of 1000 ppm (oxygen + carbon) required for application as a hydrogen storage alloy, but the results were close to that [18].

In order to investigate the influence of non-metallic impurities on the phase change of Fe-Ti ingots, an X-ray diffraction analysis was performed as shown in Fig. 3(c).

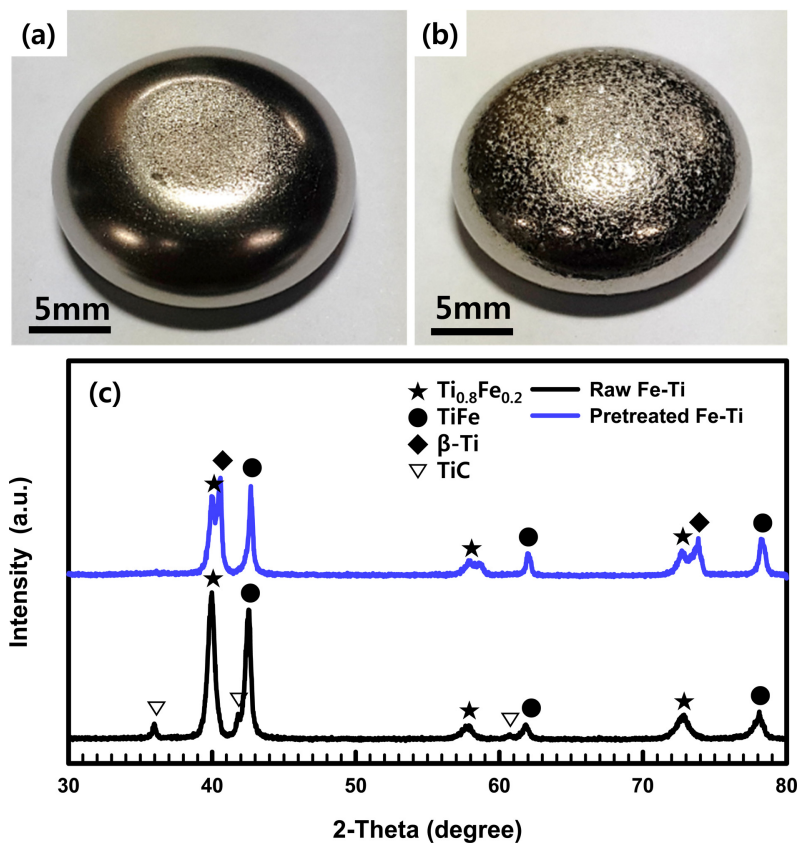

Fig. 3. Appearance of arc-melted Fe-Ti ingots: (a) raw Fe-Ti, (b) pretreated $\mathrm{Fe}-\mathrm{Ti}$, (c) XRD pattern of the Fe-Ti ingot.

Table 2. Content of gaseous impurities in the raw and pretreated FeTi ingots (ppm).

\begin{tabular}{ccccc}
\hline \hline Fe-Ti ingot & Oxygen & Nitrogen & Carbon & Total \\
\hline Raw Fe-Ti & 1670 & 60 & 5525 & 7255 \\
Pretreated Fe-Ti & 1060 & 30 & 275 & 1365 \\
\hline
\end{tabular}


Table 3. Lattice parameters and d-spacing of TiFe, $\mathrm{Te}_{0.8} \mathrm{Fe}_{0.2}$ and TiC.

\begin{tabular}{ccccccc}
\hline \hline \multirow{2}{*}{ Fe-Ti ingot } & \multicolumn{2}{c}{ TiFe $(\mathrm{nm})$} & \multicolumn{2}{c}{$\mathrm{Te}_{0.8} \mathrm{Fe}_{0.2}(\mathrm{~nm})$} & \multicolumn{2}{c}{$\mathrm{TiC}(\mathrm{nm})$} \\
\cline { 2 - 7 } & Lattice parameter & d-spacing & Lattice parameter & d-spacing & Lattice parameter & d-spacing \\
\hline Raw Fe-Ti & 0.3002 & 0.2126 & 0.3189 & 0.2256 & 0.4317 & 0.2496 \\
Pretreated Fe-Ti & 0.2992 & 0.2117 & 0.3185 & 0.2253 & none & none \\
\hline
\end{tabular}

From the XRD results, it was found that $\mathrm{Ti}_{0.8} \mathrm{Fe}_{0.2}$ and TiFe phases were formed as the main phases in both of the Fe-Ti ingots; and a $\beta$-Ti phase can also be found in the pretreated Fe-Ti. However, in the case of the raw Fe-Ti, the analysis shows that a TiC compound was formed without any $\beta$-Ti phase. This is because carbide is formed as a result of the high carbon content in the ingot. $\mathrm{Ti}$ is consumed to form carbide, and the composition is moved to the process point of the Ti-Fe alloy so that the $\beta$-Ti phase is not formed. The TiC and high carbon content are known to degrade the hydrogen storage capacity in hydrogen storage alloys $[18,19]$. Based on the XRD results for the raw $\mathrm{Fe}-\mathrm{Ti}$ and pretreated $\mathrm{Fe}-\mathrm{Ti}$ ingots, the lattice parameters of $\mathrm{Ti}_{0.8} \mathrm{Fe}_{0.2}$, the TiFe phases, and $\mathrm{TiC}$ (which are shown as columnar phases) were calculated and are shown in Table 3. Both the lattice parameters and the $\mathrm{d}$-spacing in $\mathrm{Ti}_{0.8} \mathrm{Fe}_{0.2}$ and TiFe from the pretreated Fe-Ti ingot were slightly smaller than those of the raw Fe-Ti ingot. It is believed that the amounts of oxygen, nitrogen, and carbon, which are the intrinsic elements, are reduced; and thus, the lattice structure is also affected [20].

The distribution of oxygen and carbon in the Fe-Ti ingot was analyzed by SEM and EDS and the results are shown in Figs. 4(a) - 4(f), respectively. The oxygen and carbon in the raw Fe-Ti and pretreated Fe-Ti ingots are all distributed in the internal structure, but in the case of the raw Fe-Ti ingot, it can be seen that the elemental carbon is more concentrated at the positions where the $\mathrm{TiC}$ compounds are formed. Relative quantitative analysis of $\mathrm{Ti}, \mathrm{Fe}, \mathrm{O}$, and $\mathrm{C}$ of the raw Fe-Ti and pretreated Fe-Ti ingots through EDS revealed that the peak of $\mathrm{Ti}$ and Fe was increased and the peak of oxygen and carbon was decreased in the pretreated Fe-Ti ingot.

The effect of gaseous impurities on the high-temperature oxidation properties of the Fe-Ti ingots was investigated by thermogravimetric analysis (TGA), and the results were shown in Fig. 5. Both Fe-Ti ingots were heated to $900{ }^{\circ} \mathrm{C}$ in an air atmosphere and analysed for weight change. The postoxidation temperature of the raw Fe-Ti ingot was about

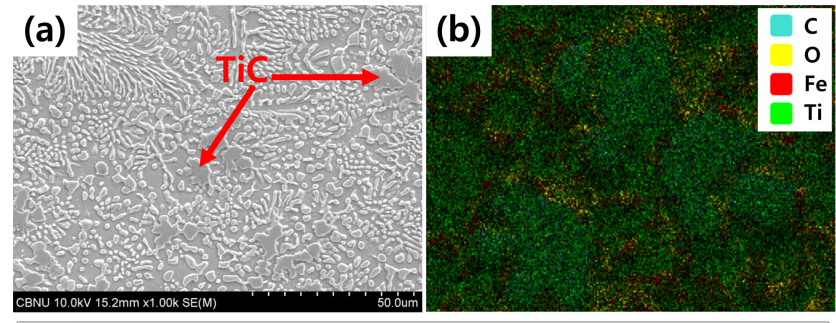

(c)

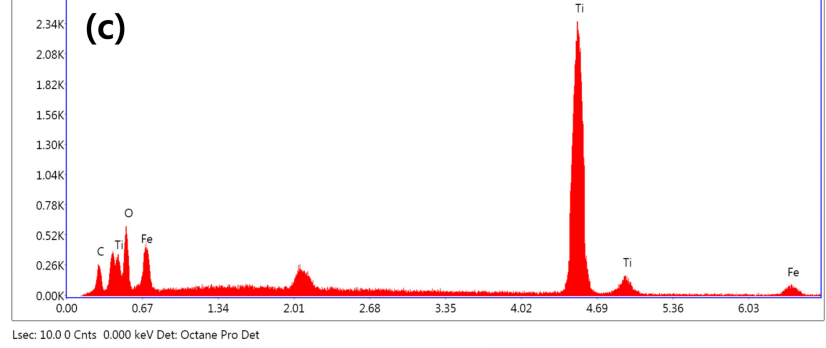

(d)

(e)

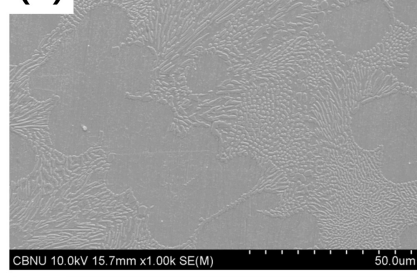

(f)

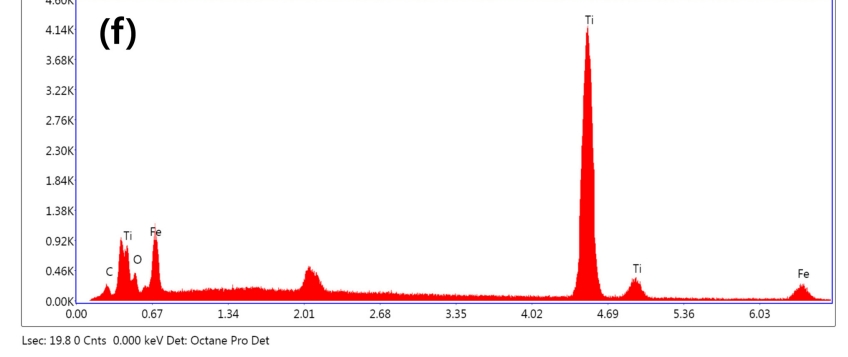

Fig. 4. SEM image and EDS analysis of raw Fe-Ti ingot: (a) microstructure, (b) EDS mapping image and (c) EDS spectrum, and the pretreated Fe-Ti ingot: (d) micro-structure, (e) EDS mapping image and (f) EDS spectrum.

$530^{\circ} \mathrm{C}$, and the weight was changed by $1.61 \mathrm{mg}$ when heated to $900{ }^{\circ} \mathrm{C}$. On the other hand, the post-oxidation temperature of the pretreated $\mathrm{Fe}-\mathrm{Ti}$ was about $710{ }^{\circ} \mathrm{C}$, and the weight was changed by $0.98 \mathrm{mg}$ when heated to $900{ }^{\circ} \mathrm{C}$. As a result, the low content of gaseous impurities in the pretreated Fe-Ti ingot seems to improve the oxidation resistance. The reason for this is that as the temperature rises, internal stress is increased 


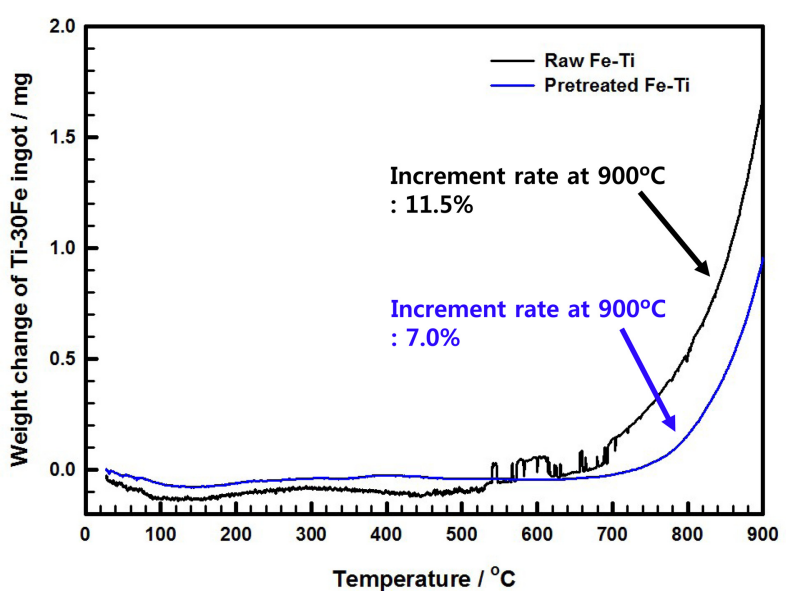

Fig. 5. TGA curve of the raw Fe-Ti and pretreated Fe-Ti ingots under air atmosphere at $10^{\circ} \mathrm{C} / \mathrm{min}$.

because of the high concentration of gaseous impurities during the process of oxide formation on the surface so that cracks in the oxide film occur and gaps between the oxide layer and the parent material occur [21,22].

\section{CONCLUSIONS}

The eco-friendly pretreatment solution of $2 \mathrm{M} \mathrm{NaOH}+$ $40 \mathrm{~g} / \mathrm{L} \mathrm{Na}_{4} \mathrm{P}_{2} \mathrm{O}_{7}$ was developed to remove oil remaining in the titanium turning scraps. After the pretreatment with this solution, up to $54.0 \%, 96.2 \%, 98.4 \%$, respectively, of the gaseous impurities of oxygen, nitrogen, and carbon were removed. Using these pretreated scraps as raw material, a FeTi ingot with low non-metallic impurity content of 1365 ppm was prepared. Fe-Ti alloy ingots with low gaseous impurity content are considered to be easy to deoxidize or to use as additives for steelmaking.

\section{ACKNOWLEDGEMENTS}

This work was supported by the Korea Institute of Energy Technology Evaluation and Planning (KETEP) and the Ministry of Trade, Industry \& Energy (MOTIE) of the Republic of Korea (No. 20185210100030).

\section{REFERENCES}

1. G. Lutjering, J. C. Williams, Titanium, pp. 7-11, Springer,
Berlin (2007).

2. J. Lu, Y. Zhang, W. Huo, W. Zhang, Y. Zhao, and Y. Zhang, Appl. Surf. Sci. 434, 63 (2018).

3. H. Asgar, K. M. Deen, Z. U. Rahman, U. H. Shah, M. A. Raza, and W. Haider, Mater. Sci. Eng. C 94, 920 (2019).

4. T. E. Norgate, S. Jahanshahi, and W. J. Rankin, J. Clean. Prod. 15, 838 (2007).

5. J. M. Oh, K. M. Roh, H. Kwon, and J. W. Lim, Met. Mater. Int. 23, 1139 (2017).

6. K. Topolski, W. Bochniak, M. Lagoda, P. Ostachowski, and H. Garbacz, J. Mater. Process. Technol. 248, 80 (2017).

7. C. I. Hong and J. W. Lim, Korean J. Met. Mater. 56, 205 (2018).

8. J. M. Oh, K. M. Roh, B. K. Lee, C. Y. Suh, W. Kim, H. Kwon, and J. W. Lim, J. Alloy. Compd. 593, 61 (2014).

9. J. M. Oh, B. K. Lee, C. Y. Suh, and J. W. Lim, J. Alloy. Compd. 574, 1 (2013).

10. M. Pourabdoli, S. Raygan, H. Abdizadeh, and K. Hanaei, Can. Metall. Q. 46, 17 (2007).

11. W. Gordon and A. Bennekom, Mater. Sci. Technol. 12, 126 (1996).

12. M. Panigrahi, R. K. Paramguru, R. C. Gupta, E. Shibata, and T. Nakamura, High Temp. Mater. Proc. 29, 495 (2010).

13. J. M. Oh, B. K. Lee, G. S. Choi, and J. W. Lim, J. Korean Inst. Resour. Recycling 21, 60 (2012).

14. J. E. Lee, N. C. Cho, C. M. An, J. S. Noh, and J. H. Moon, Clean Tech. 19, 264 (2013).

15. H. M. Kim, F. Miyaji, T. Kokubo, and T. Nakamura, J. Ceram. Soc. Jpn. 105, 112 (1997).

16. S. B. Lee, K. H. Joeng, and J. D. Lee, Appl. Chem. Eng. 21, 301 (2010).

17. H. T. Yeom and J. S. Lee, Plating and surface finishing, pp. 95, Munundang, Korea (2008).

18. C.-H. Li, J. He, Z. Zhang, B. Yang, H.-Y. Leng, X.-G. Lu, Z.-L. Li, Z. Wu, H.-B. Wang, J. Alloy. Compd. 618, 679 (2015).

19. S. M. Lee and T. P. Perng, Int. J. Hydrogen Energy 25, 831 (2000).

20. B. D. Cullity and S. R. Stock, Elements of X-ray Diffraction 3rd Ed., pp. 61-62, Prentice-Hall, New Jersey (2001).

21. N. Birks, G. H. Meier, and F. S. Pettit, Introduction to the High-Temperature Oxidation of Metals, pp. 24-27, Cambridge University Press, New York (2006).

22. E. A. Gulbransen and S. A. Jansson, Oxid. Metals 4, 181 (1972). 